\title{
¿QUÉ ES LA OFICINA DE ORIENTACIÓN UNIVERSITARIA?
}

\author{
Luis Vólmar Quintero P. MD. MSc*
}

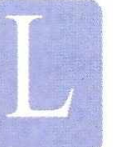

a Fundación Universitaria de Ciencias de la Salud desde el mes de mayo de 2002 ha puesto a disposición de toda la comunidad universitaria los servicios de la Oficina de Orientación Universitaria. Actuó como su Director hasta febrero de 2008 el Dr. Luis Carlos Taborda R., actual Vicerrector Académico, fecha en la que me fue encomendada esa importante labor; quiero agradecer a este medio informativo la oportunidad para difundir cuáles son nuestras actividades.

Se trata de una dependencia subordinada de la Vicerrectoría Académica, con la idea fundamental de desarrollar una serie de actividades de manera independiente a la malla curricular, cuya misión sea brindar un espacio de apoyo a los alumnos en aquellos aspectos que puedan afectar no sólo las actividades académicas, sino su vida personal o familiar. La meta es buscar el óptimo crecimiento y desarrollo personal y por supuesto, en sus estudios. Además de lo anterior, dar el apoyo requerido a las diferentes facultades y sus docentes para la evaluación y el seguimiento correspondiente de casos puntuales.

Para lograr esto se han diseñado y puesto en funcionamiento estrategias que destacamos a continuación.

Consulta psiquiátrica o psicológica: trata de contribuir a la identificación, evaluación y planteamiento de posibles soluciones en aquellas situaciones que pueden interferir el crecimiento personal, afectivo, social o académico, ya sea por la presencia de una reacción adaptativa, una disfunción familiar o como hemos logrado identificar en algunos casos, por algún trastorno emocional subyacente; hay que agregar que a veces es necesario involucrar a los padres para el manejo adecuado de una situación en particular. Por supuesto, cuando se requiera, se hará la derivación al profesional de la salud

Médico especialista en Psiquiatría. Magíster en Bioética, Director de Orientación Universitaria, Profesor Asociado, Facultad de Medicina, Departamento de Psiquiatría, Fundación Universitaria de Ciencias de la Salud. Bogotá D.C. Colombia.

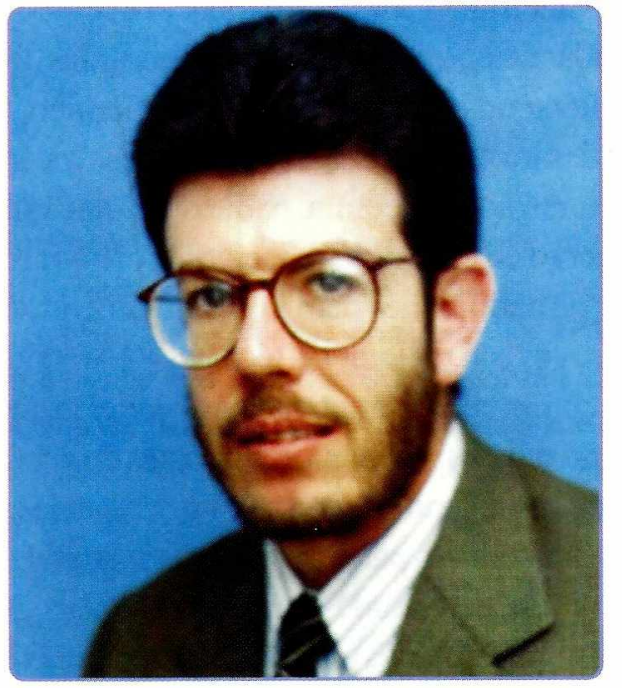

específico con el consiguiente seguimiento por parte de la oficina. Hemos identificado, por ejemplo, que el hecho de empezar a vivir en una ciudad diferente con el consecuente cambio de sitio de vivienda, con costumbres nuevas y con un nuevo rol como estudiante universitario, constituyen factores de riesgo muy importantes que pueden traer como consecuencia estruendosos fracasos académicos; es así como diseñamos con el apoyo de Bienestar Universitario las estrategias para introducir al estudiante en lo que significa vivir en nuestra ciudad, con la participación de catedráticos expertos en el tema, incluida una visita a los lugares de importante valor cultural e histórico de la ciudad.

Orientación vocacional: esta actividad se ofrece a los estudiantes para que identifiquen sus habilidades y aptitudes que les permitan una mayor claridad en la toma de decisiones significativas para su vida.

Programas de desarrollo personal: una vez identificados los temas de acuerdo con necesidades específicas, se han diseñado una serie de talleres, foros, conferencias o grupos de discusión, que buscan resolver cuestionamientos propios de la juventud actual. Es así como hace poco se 
planeó y se puso en práctica un taller de convivencia, que tuvo como motivación la presencia de situaciones concretas en algunos estudiantes; en corto plazo lo haremos extensivo al primer semestre de todas las facultades, como parte de las tácticas planeadas en diferentes instancias para dar respuesta a esta difícil situación. Existen otros temas como el taller de competencias estudiantiles cuyo objetivo es facilitar a los estudiantes el acceso a herramientas didácticas, que le permitan mejorar las destrezas para garantizar un buen rendimiento académico, favoreciendo su desarrollo personal integral; allí se tocan temas como comprensión de lectura, hábitos y técnicas de estudio, y refuerzo en escritura, redacción y ortografía. Otro es el taller de habilidades para el desempeño académico cuyos objetivos son mejorar las técnicas y estrategias para aprender, comprender, practicar y aplicar el proceso enseñanza-aprendizaje; aplicar los esquemas de pensamiento lineal, lógico y lateral que permitan potenciar la creatividad como fundamento para el pensamiento crítico; conocer y aplicar las habilidades para escuchar, preguntar y tomar decisiones; además promover el trabajo en equipo, habilidad tan importante en el desempeño académico y profesional de hoy. Otro más, es el de habilidades para la vida cuyo objetivo es identificar la importancia de planear el proyecto de vida, encontrar estrategias para una comunicación efectiva, la solución de conflictos y el crecimiento personal en los futuros profesionales. Uno que reviste gran importancia es el de salud sexual y reproductiva que busca promover estilos de vida saludables y una sexualidad responsable. La preocupación al evidenciar de tiempo atrás la presencia de embarazos no deseados y sus complicaciones, motivó la creación de este taller que era necesario realizarlo en los primeros semestres; como quedó demostrado, los resultados positivos no se hicieron esperar, lográndose la disminución de esta situación en un corto tiempo. Como complemento hay que resaltar que en conjunto con Bienestar Universitario y Medicina Social y Comunitaria, se ha establecido un programa de consultoría en salud sexual y reproductiva que se lleva a cabo los todos los miércoles en las horas de la mañana.

Otra actividad que se desarrolla en Orientación Universitaria, también con la participación de expertos, es el apoyo a la Oficina de Admisiones con la aplicación de pruebas psicotécnicas y la realización de entrevistas para los aspirantes de las cuatro facultades en sus programas de pregrado y de posgrado en medicina y enfermería; de igual manera el apoyo y activa participación en las políticas antideserción mediante las tutorías académicas, así como en el Comité que con este objetivo cuenta la Fundación.

Merece una especial mención el tema de las tutorías: esta actividad desarrollada por estudiantes de semestres superiores como una materia electiva y dirigida a los estudiantes de los primeros semestres, tiene como ventajas el fomento de la integración entre pares, con la indudable ventaja al acumular y compartir enseñanzas y experiencias propias de la vida académica con personas de su misma generación, todo bajo la supervisión de un profesional especializado.

También acompañamos a las facultades en sus reuniones con los padres de familia, en las que se busca informar cómo van sus hijos no sólo en los estudios sino en su adaptación al ambiente universitario. De otra parte, participamos también con foros o conferencias en colegios para la divulgación de temas actuales de interés general como la dependencia a sustancias, juego patológico o suicidio en adolescentes; están dirigidos a estudiantes, profesores y padres de familia. Con esto se busca además, posicionar a la Fundación Universitaria como líder en las actividades de promoción de estilos de vida saludables y en la prevención de tales patologías.

Una actividad más que hemos venido desarrollando desde hace cerca de un año, es la coordinación de las denominadas asignaturas comunes, es decir informática, inglés y psicología. Esta importante labor ha venido en aumento, hasta el punto que teniendo el cuenta las directrices dadas en el PEI, muy recientemente entró en vigencia el Centro de Idiomas, que cuenta ya con su propia coordinación e independencia.

Por último, quiero mencionar que el hecho de contar con dos sedes hospitalarias, nos da la oportunidad de prestar nuestros servicios en ambos lugares; como se sabe, está la sede en el tercer piso del centro de salud al lado del Hospital de San José y en la actualidad se están adaptando los espacios necesarios en el Hospital Infantil Universitario de San José. 